\title{
ESCENA
}

Publicación semestral. ISSN 2215-4906

Volumen 80 - Número 1

Julio - Diciembre 2020

\section{De objeto a cosa. Una reflexión para comprender la pornografía}

\author{
From object to thing. A reflection for understanding \\ pornography
}

Natasha Alpízar Lobo

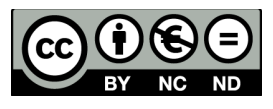

Esta obra está bajo una licencia Creative Commons Reconocimiento-No comercial-Sin Obra Derivada 


\title{
De objeto a cosa. Una reflexión para comprender la pornografía
}

\author{
From object to thing. A reflection for understanding \\ pornography
}

\author{
Natasha Alpízar Lobo ${ }^{1}$ \\ Universidad de Costa Rica \\ Costa Rica
}

Recibido: 19 de agosto de 2019 Aprobado: 21 de febrero de 2020

\begin{abstract}
Resumen
Las aproximaciones esencialistas y constructivistas a la pornografía suelen concebirse como antagónicas o contrarias. Esto porque, de un lado, se entiende la pornografía desde el contenido de las representaciones y, de otro, desde la emoción y la excitación de quien consume imágenes. No obstante, pese a esos esfuerzos de diferenciación, este ensayo argumenta que hay un denominador común entre ambas: la pornografía se ubica como imagen, es decir, como objeto (acabado, tiene una forma, es un producto). A través de una investigación etnográfica realizada en una comunidad online, Foro de Costa Rica, el ensayo propone pensar la pornografía como cosa o proceso (inacabado, está siempre tomando forma, en constante producción). Esto pretende alejarse de las visiones dicotómicas entre lo esencial y lo construido. Como cierre e invitación, se destaca la importancia social de considerar un posicionamiento como este.
\end{abstract}

Palabras clave: pornografía; objeto; imagen; cosa; proceso

1 Docente en la Escuela de Antropología, en la Escuela de Ciencias Políticas y en el Departamento de Ciencias Sociales de la Universidad de Costa Rica. Máster en Antropología Social por la Universidad de Costa Rica. ORCID: 0000-0001-9846-0643. Correo electrónico: natasha.alpizar@ucr.ac.cr

ESCENA. Revista de las artes, 2020, Vol. 80, Núm. 1, pp. 262-282 ISSN 2215-4906 


\begin{abstract}
The essentialist and constructivist approaches to understanding pornography are usually conceived of as antagonistic or contradictory. This is because, on the one hand, pornography is understood through a focus on the content of the representations and, on the other hand, it is explored in terms of the emotions and excitement of those who consume the images. However, despite these seemingly different approaches, this essay argues that there is a common denominator among both: pornography is analyzed as an image; in other words, it is an object (something that is finished, has a shape, is a product). Through an ethnographic investigation carried out in an online community, Foro de Costa Rica, the essay suggests we think about pornography as a process (unfinished, always taking shape, constantly in production). This aims to move away from the dichotomous vision of the essential or the constructed. As a closure and an invitation, the essay stresses the social importance that this theoretical intervention allows.
\end{abstract}

Keywords: pornography; object; image; thing; process 


\section{Introducción}

El 11 de agosto del 2018, un profesor de la Universidad Autónoma de Monterrey (UNAM) me invitó a su clase con el propósito de compartir algunas reflexiones sobre pornografía. Para el desarrollo de la discusión que deseaba plantear, descargué dos imágenes que el buscador Google categorizaba como "pornografía". Una era de una bebé desnuda, sentada en una superficie con fondo blanco. La otra era de dos hombres jóvenes, desnudos, de pie sobre un fondo y una superficie negra. Pegué esas dos imágenes en la pizarra de la clase y, luego de una breve presentación, pregunté al grupo - de siete personas-: "¿qué ven ustedes aquí?". Inmediatamente, una de las personas dijo "un bebé desnudo". Debido la distancia en que se encontraban de la imagen, se empezó a discutir si era un bebé o una bebé, porque no se visualizaban con claridad los genitales. Sobre la otra imagen, una persona mencionó "veo a un hombre negro y a un hombre blanco" y otra expresó "yo veo a dos gais". Esto inició un debate sobre por qué veían "gais" o "qué era lo gay" en la imagen.

El espacio para discutir todas las apreciaciones de ese momento duró aproximadamente cinco minutos y durante ese tiempo nadie mencionó que veía o estaba viendo "pornografía". El ejercicio que intentaba plantear era tomar un material que había sido categorizado por Google como "pornografía" y problematizarlo dentro de un grupo específico a quienes no les pregunté "¿ven pornografía?" o “¿consideran que las imágenes son pornográficas?", sino más bien "¿qué ven?". De fondo, lo que buscaba explicar en aquella ocasión era la distinción entre el tratamiento de la pornografía como hecho (forma-completa, objeto acabado, producido) y el tratamiento como proceso (de tomar-forma, cosa inacabada, en producción).

Esta es la misma idea que planeo discutir a lo largo de este ensayo. Un volumen importante de la producción académica sobre pornografía está en clave "esencialista" y "constructivista". A esto también se le conoce como los debates "objetivos" y "subjetivos" de la pornografía, respectivamente. En este documento, deseo trabajar sobre la manera en cómo se conectan tales discusiones que, huelga decir, se han concebido como antagónicas. Se argumentará que cada una de estas aristas circunscribe la pornografía como un objeto o hecho, ya que casi siempre tienen el mismo punto de partida (las imágenes).

El ensayo no se adscribe a ninguna de las líneas mencionadas y tampoco contribuirá a seguir reafirmando o legitimando la división que existe entre sí. Más bien se propone pensar la pornografía como cosa o proceso y así dar énfasis a su estatus potencial y transformación. Con esto, se sostiene que la pornografía no es una cuestión de imágenes, es una cuestión de relaciones en entornos constantemente en desarrollo. Dicha reflexión trata de empatar con las críticas hechas a los dualismos esencial-construido, que abogan por procesos y en los cuales cobra relevancia el devenir. En este sentido, el ensayo no se trata de una nueva propuesta conceptual, sino una revaloración comprensiva sobre la pornografía.

ESCENA. Revista de las artes, 2020, Vol. 80, Núm. 1 (julio-diciembre), pp.262-282 
Ahora bien, para abordar todo lo anterior, el texto se estructura de la siguiente manera: en la primera parte se elabora una argumentación un poco más detallada de las líneas "esencialistas" u "objetivas" y las "construccionistas" o "subjetivas". En la segunda parte, esto se conecta con las investigaciones recientes en las Ciencias Sociales. Ello no aspira a ser una reconstrucción histórica y no obedece necesariamente a un orden cronológico. Hasta aquí, intentaré demostrar que a lo largo de mucho tiempo la pornografía ha ocupado un lugar legítimo como objeto o hecho.

En la tercera parte expongo una descripción etnográfica de la pornografía en la comunidad online Foro de Costa Rica y es a partir de eso que, en la cuarta parte, propongo comprender la pornografía como cosa o proceso a través de una elaboración conceptual. A manera de cierre, menciono la relevancia que este tipo de posicionamientos puede tener en distintos ámbitos, como el judicial.

\section{Esencia o construcción}

Cuando se trata de pensar la pornografía se han desarrollado dos grandes líneas comprensivas: una esencialista y la otra constructivista. Ambas corresponden a lo que Ruwen Ogien (2005) categoriza como la forma "objetiva" y la forma "subjetiva" de definir la pornografía. Para el autor, los enfoques agrupados en la primera línea "solo aluden a la forma y el contenido de las representaciones" (Ogien, 2005, p. 50). Los segundos, en cambio, "refieren a los estados mentales o afectivos del autor, el consumidor o del no consumidor" (Ogien, 2005, p. 50).

Dichas líneas reflejan, de una u otra forma una fijación en los objetos. Este marco de comprensión permea, si bien no todas, sí la gran mayoría de las discusiones, antiguas y recientes. Por ejemplo, el problema de la definición de la pornografía ha sido una constante, inclusive antes de la legalización (o despenalización) en países occidentales. Walter Kendrick (1995) destaca que en ciertos diccionarios ingleses -como el médico, de 1857, y el Oxford English Dictionary en 1909- se podían encontrar algunas definiciones vinculadas a la representación de prostitutas y la lascivia. No había del todo un acuerdo sobre su definición y tampoco sobre la aparición propiamente dicha de la palabra en los diccionarios. Pero, exactamente de este mismo problema suele encargase el campo de la jurisprudencia y el de la filosofía, en donde, huelga decir, no ha habido un mínimo acuerdo. Desde finales de la década de 1960 y en adelante, en la creación de comités y comisiones en distintas latitudes (Comité Williams en Inglaterra, Comisión Johnson y la Comisión Meese en Estados Unidos, el Comité Fraser en Canadá) lo que ha generado tensas disputas es la dificultad de consensuar una definición que facilite la distinción con propósitos de sancionar o criminalizar la pornografía.

Así pues, el ejercicio constante por la distinción de la pornografía respecto a otros materiales es recurrente y un punto fundamental del debate. En este sentido, el 
establecimiento de un límite entre el erotismo y la pornografía o el arte y la pornografía resulta un tema de profunda preocupación. Las posiciones más "esencialistas" van a reafirmar una división objetiva entre sí (Baudrillard, 1981, 1994; Lawrence, 2013). Por el contrario, las posiciones más "constructivistas" plantearán que la distinción es subjetiva, arbitraria y cambiante (Llorente, 2017; Ogien, 2005; Osborne, 2002; Sontag, 2014). Sin embargo, no se alejan de dar centralidad a las imágenes, la representación, los objetos.

Empero, no es solo el problema de la definición de la pornografía lo que instaura un campo de disputas, sino también su adjetivación. Tanto la producción académica sobre la definición como la reflexión sobre la adjetivación apuntan a objetos. Se puede citar a Ruwen Ogien (2005) y Naief Yehya (2012), quienes retoman algunas categorizaciones de tipo "X" (cintas para adultos), "XXX" (cintas hardcore) y "XXXXX" (contenido extremo o crades). Asimismo, tienen lugar aquellas denominadas softcore y hardcore que, a menudo, y con mucha insistencia, se precisan como géneros opuestos: el primero se caracteriza como simulación, sin enfoques de genitales; contrario al segundo, que muestra con planos cerrados la felación, la eyaculación, el coito anal, vaginal y oral (Gubern, 2005; Retana, 2008). En algunos textos, dicha oposición entre softcore y hardcore alude a qué tan explícitas o crudas son las imágenes y films (Azar, 2014). Lo anterior se reproduce casi de manera acrítica o en automático, sin profundizar.

Separado de las distinciones retomadas, las adjetivaciones no terminan ahí. Erika Lust en su libro Porno para mujeres (2008) hace distinción entre "porno para hombres" y "porno para mujeres". Parte las características que les distingue, según la autora, refieren a los contenidos, los cuales se exponen y comparan en la Tabla 1. Es posible ubicar el planteamiento Lust (2008) en una tendencia constructivista. Sin embargo, de fondo hace creer que las mujeres, en general, solo se excitan si hay emociones, si todo es más dulce y consentido, lo que puede conllevar a una esencialización de género y formas de deseo equivocadas (Tena Aguiar, 2015). La adjetivación de Lust, en este caso, parte no solo de objetos (cine), sino que pone a jugar el uso del sentido común y exclusión respecto a la sexualidad. Sobre esto último, Loreto Ares y Sara Pedraz Poza (2011) critican la categorización de "porno para mujeres" y se preguntan

¿Qué entiende [Erika] Lust por chicas y chicos normales? ¿Las mujeres modernas y trabajadoras excluyen a las mujeres precarias? ¿A las protagonistas tiene que gustarles, como normales que son, la decoración y la moda? ¿Armani? Parece que la descripción de Lust es igualmente excluyente. (2011, p. 105) 
De objeto a cosa. Una reflexión para comprender

la pornografía

Tabla 1. Comparación del cine para hombres y el cine para mujeres

\begin{tabular}{|c|c|c|}
\hline Tipo & Cine para hombres & Cine para mujeres \\
\hline \multirow{8}{*}{ Características } & Mamada hasta el fondo de la garganta. & Sexo oral practicado a la chica. \\
\hline & Mansiones de lujo. & $\begin{array}{l}\text { Una habitación con interiorismo mo- } \\
\text { derno. }\end{array}$ \\
\hline & $\begin{array}{l}\text { Mafiosos, traficantes, espías, militares, } \\
\text { carceleros... }\end{array}$ & $\begin{array}{l}\text { Chicos normales a nuestro alrede- } \\
\text { dor, nuestros amigos. }\end{array}$ \\
\hline & $\begin{array}{l}\text { Putas rubias, ninfómanas, lesbianas } \\
\text { que tienen sexo con hombres, agentes } \\
\text { secretas asesinas, adolescentes ... }\end{array}$ & $\begin{array}{l}\text { Mujeres modernas, trabajadoras, } \\
\text { emancipadas, normales, como tú y } \\
\text { tus amigas. }\end{array}$ \\
\hline & $\begin{array}{l}\text { Coches deportivos, motos acuáticas, } \\
\text { helicópteros, jets privados... }\end{array}$ & $\begin{array}{l}\text { Un iPhone, un Mac, un Mini, una } \\
\text { Vespa... }\end{array}$ \\
\hline & Las mujeres están siempre dispuestas. & $\begin{array}{l}\text { Hay que ganarse el sexo, no me } \\
\text { abro de piernas solo porque tú me } \\
\text { lo pidas. }\end{array}$ \\
\hline & $\begin{array}{l}\text { Las mujeres violadas en el fondo dis- } \\
\text { frutan. }\end{array}$ & Sexo siempre consentido. \\
\hline & $\begin{array}{l}\text { Medias de rejilla, minifalda de puta, top } \\
\text { minúsculo, zapatos imposibles de ta- } \\
\text { cón y plataforma... }\end{array}$ & $\begin{array}{l}\text { Un vestido lindo de Miss Sixty, de } \\
\text { Armani o de Mango, unos tejanos y } \\
\text { una camiseta... }\end{array}$ \\
\hline
\end{tabular}

Fuente: Elaboración propia a partir de Lust (2008, p. 24).

Ahora bien, muchas más adjetivaciones tienen lugar junto a la propuesta de clasificar y diferenciar el "porno para mujeres". En tendencias deconstruccionistas y posmodernas hoy día es posible encontrar planteamientos sobre el "porno gonzo" (Echavarren, 2014) y la "pornografía amateur" (Yehya, 2012), las cuales suelen ser definidas como producciones de bajo presupuesto, sin elaboraciones acabadas y elaboradas por personas "comunes y corrientes". Además, existen reflexiones que plantean el surgimiento de la "pospornografía", un género definido como "carne + política" (Echavarren, 2014, p. 61) o como "aquellas producciones audiovisuales nacidas como crítica y construcción de representaciones de sexualidades no dominantes" (García del Castillo, 2011, p. 362). Por su parte, Fabián Giménez Gatto (2015), bajo esta misma lógica basada en la tematización de imágenes, propone hablar de pospornografías en plural (pornoclastia y pornolatría, metapornografía y parapornografía), además de concebir las "pornografías de otro modo" (pornografía espectral, pornografía de autor y pornografía expandida).

ESCENA. Revista de las artes, 2020, Vol. 80, Núm. 1 (julio-diciembre), pp. 262-282 
Podemos seguir engrosando la lista de las adjetivaciones, pero el objetivo del ensayo no es hacer un recuento de todas y cada una de estas. Antes bien, la intención es mostrar que, por más creativas y sugerentes que puedan ser, las clasificaciones emergen a partir de una diversidad en las imágenes (el contenido o el propósito que se les adjudique). Hay una evaluación abstracta en sí mismas, sin que medie un análisis de procesos de negociación y de los entornos. Cuando se intenta definir o cuando se intenta adjetivar, ya sea de forma esencialista o constructivista, el punto de partida sigue siendo el mismo.

\section{Comprensión como hecho u objeto}

Es interesante ver que muchas de las interrogantes en la investigación social coinciden en la ubicación de la pornografía como objeto o como un hecho. Como argumentaré, a continuación, cuando se trata de campos más exploratorios, empíricos o experimentales, llama la atención que haya un punto de encuentro vinculado a la focalización en las imágenes para estudiar o comprender la pornografía.

Ciertas referencias académicas se han ocupado por trazar y hacer recuento de las primeras indagaciones hechas sobre la pornografía. Arcand (1993) y Ogien (2005) señalan que, después de la segunda mitad del siglo XIX, buena parte de las investigaciones en ciencias sociales -psicología y sociología- giraban en torno a la preocupación por los efectos de la pornografía. Desde un inicio, se buscaba la correlación entre esta y la violencia o criminalidad de carácter sexual. Tres líneas de análisis eran el norte de aquellas indagaciones: "el efecto negativo" o las "teorías de la imitación"; "el efecto neutral", y "el efecto positivo" o "las teorías de catarsis o evasión".

Muchas de las investigaciones, de corte conservador, influenciadas y financiadas por las élites políticas de la época, son contradictorias en sus planteamientos y resultados. Para quienes defendían que la pornografía no tiene efecto alguno o tiene un efecto positivo estaba presente la "liberación" y calma de algunas represiones o crímenes potenciales. Para quienes defendían que la pornografía tiene efectos negativos había un aprendizaje de la violencia; peligrosas consecuencias psicológicas y sociales a partir del consumo. En un lado y en el otro los hallazgos no eran concluyentes. No solo porque la conexión entre consumo y comportamiento cada vez se volvió más cuestionable y menos convincente, sino porque, además, al tratarse, principalmente, de investigaciones de laboratorio -es decir, en un ambiente "artificial" con una selección de poblaciones específicas (sin una certeza o validez representativa) - no parecían reflejar muy bien lo que acontece en un conjunto y complejidad de interacciones dentro de un entorno. En este sentido, no primó en absoluto una pregunta por las condiciones "naturales" de las personas en relación con 
la pornografía. ${ }^{2}$ Antes bien se le extrajo de cualquier posibilidad contextual. Así, la pornografía y las personas se tomaron como entes estáticos y no procesos en movimiento.

Es importante tener noción sobre la tónica que ha existido en las investigaciones de antaño. Si echamos un vistazo a la producción académica reciente, aunque las preguntas, metodologías y marcos teóricos han variado considerablemente, lo cierto es que siguen dando énfasis a las imágenes y rara vez a los entornos. En la última década, es muy recurrente encontrar que la mayoría del material de análisis para estudiar la pornografía refiere al contenido de imágenes, ya sea fotografías, vídeos o películas (Ares \& Pedraz Poza, 2011; del Barrio-Álvarez \& Garrosa, 2015; González Ramírez, 2011; Monge-Nájera \& Vega Corrales, 2013; Tenorio Pangui, 2015; van Doorn, 2010; Zhou \& Paul, 2016). Fuera de esto, también es posible encontrar investigaciones en donde no hay o no se especifica concretamente el material de análisis para discutir sobre pornografía (Erchull \& Liss, 2014; Griffith, Adams, Hart, \& Mitchell, 2012; Salinas Hernández, 2011). Son todavía escasas las investigaciones que contemplan poblaciones concretas e indagan elementos más relacionales, contextuales y subjetivos (Díaz-Benítez, 2009, 2013; Guillén Rauda, 2013, 2014; Leal Guerrero, 2013; Parreiras, 2010a, 2010b, 2016)

Pese a que las inquietudes y preocupaciones se han diversificado, ya que no solo permanece un afán por explorar correlaciones entre pornografía y violencia o crimen, sino que también hay nuevas indagaciones sobre las tecnologías digitales, producción y consumo. Existen, además, intereses sobre las distintas apropiaciones culturales y políticas de movimientos en pro de la diversidad sexual, la democracia y la justicia. Sin embargo, sigue latente la determinación de las imágenes en términos analíticos (es un objeto). Asimismo, en esta variedad de indagaciones hay una suerte de "sentido común" cuando se habla de pornografía, dado a que no se brinda una discusión sobre cómo se está entendiendo. Pero, además, las investigaciones suponen, en la mayoría de las ocasiones, que efectivamente las poblaciones de estudio o grupos concretos poseen una comprensión igual u homogénea, en términos de tiempo y espacio, cuando se dice "pornografía" (o sea, implícitamente, la pornografía se considera un hecho).

2 No pretendo tomar de manera acrítica las nociones sobre lo "artificial" y lo "natural" de los ambientes o contextos. A falta de una mejor denominación, ambas palabras en el texto aparecen entrecomilladas solo para hacer una distinción entre el tipo de entorno que implica un laboratorio (donde frecuentemente se usaban pletismógrafos en el pene o fotopletismógrafos en la vagina como instrumentos de medición) respecto a otro tipo de entorno como la casa habitación, una sala de cine, entre otros.

ESCENA. Revista de las artes, 2020, Vol. 80, Núm. 1 (julio-diciembre), pp. 262-282 


\section{Comunidad y pornografía}

La propuesta comprensiva que deseo mostrar surge de la realización de una etnografía en la comunidad online Foro de Costa Rica ${ }^{3}$. El propósito de la investigación se relacionaba con las formas de comprender y vivir la pornografía -que, en sus inicios, entendí, también yo, como un objeto-. El trabajo de campo inició en el año 2012 y finalizó en el año 2015. Se aplicaron técnicas como la observación participante, la entrevista a profundidad y el análisis de fotografías publicadas en el foro. No obstante, debido al intenso involucramiento en el trabajo de campo, muchas de las ideas respecto a la comprensión de la pornografía cambiaron de manera sustancial. En un principio, la investigación tenía como norte saber cómo y por qué existía la pornografía en esta comunidad. Pero, luego, este norte derivó en la necesidad de conocer en profundidad la comunidad para así entender la pornografía.

En este sentido, el aspecto más relevante por mencionar sobre el foro es que estaba dividido antagónicamente: la parte de "arriba" y la parte de "abajo". A primera vista, no existen elementos explícitos o físicos para establecer una diferenciación clara y tajante entre una parte u otra. Por lo que, una persona externa a la comunidad no sabría en dónde empieza o termina "arriba" y "abajo"; es decir, la división no es autoevidente. En su defecto, esta frontera simbólica tiene valor únicamente para las personas y las prácticas cotidianas que se desarrollan a lo interno del colectivo del foro.

El foro se compone de cinco grandes categorías: "Antiteatro", "Comunidad", "Entretenimiento", "Foros temáticos" y "Contenido adulto". Lo que las personas denominan parte de "arriba" refiere a todo lo que se encuentra dentro de cada una de las categorías, a excepción de "Contenido Adulto". Esta última es lo que llaman la parte de "abajo" -a veces también denominada como "Zona peluche"- y es el lugar autorizado dentro del foro para la publicación de imágenes determinadas como pornografía y para la promoción de trabajo sexual. Por lo general, el material es creado y administrado por población masculina heterosexual o por nicknames masculinizados. En raras ocasiones, la población femenina o los nicknames feminizados crean y comparten pornografía, a excepción de las trabajadoras sexuales.

No está de más mencionar que la distinción que se hace entre nicknames masculinizados y nicknames feminizados no es arbitraria. El sistema binario del género es muy importante para quienes se mueven dentro del foro, sea "arriba" o "abajo". Justamente por ello, existen diversas estrategias para dar con esta información de las personas, cuando no la manifiestan explícitamente o hay ambigüedades al respecto. Esto hace que la comunidad sea profundamente heteronormativa.

${ }^{3}$ En adelante, denominada "el foro". Su sitio web es www.forodecostarica.com.

ESCENA. Revista de las artes, 2020, Vol. 80, Núm. 1 (julio-diciembre), pp.262-282 
A diferencia de la "parte de abajo", en la "parte de arriba" no está permitida la pornografía. Sin embargo, durante el trabajo de campo hubo una actividad, llamada "Miss y Mr. Foro", en la cual la frontera simbólica se volvió ambigua. El concurso como tal consistió en subir fotografías propias con el objetivo de "conocerse", "ponerle una cara al nick" y "vacilar". El contenido del material varió en términos de exposición de cuerpos y en muchas ocasiones las imágenes son similares o idénticas a las publicadas en la "parte de abajo". La lectura e interpretación de la comunidad sobre esto es múltiple: hay quienes opinan que estas imágenes son pornografía, hay quienes opinan que no lo son y hay quienes mencionan que es "erotismo".

¿Por qué se daba la distinción entre el material publicado en la "Zona Peluche" y el concurso "Miss y Mr. Foro"? ¿Cómo y por qué surge la frontera simbólica de "arriba" y "abajo" que permea la comprensión de la pornografía? Buscar una respuesta implicó comprender los procesos constitutivos de la comunidad. Cuando el foro se crea, en el año 2006, según las personas, no había pornografía y tampoco existía un "arriba" y un "abajo". Se podría decir que el foro era unitario, lo cual no implicaba necesariamente una armonía, porque siempre hubo ejercicios de poder, conflictos y confrontaciones. Un cambio de administración en la página web del foro propició modificaciones en varias dinámicas, entre ellas el tipo de publicaciones que se hacían y el material que se compartía. Se creó una zona de "Contenido adulto" con el objetivo de publicar pornografía y ofrecer servicios de trabajo sexual femenino. Esto atrajo una población interesada por este tipo de material y servicios.

Si bien muchas personas no estaban de acuerdo con las ideas y disposiciones de la nueva administración de la página, no querían retirarse o buscar otro espacio de socialización, pues había una dimensión de entretenimiento, amistad y discusión colectiva que la página del foro facilitaba. La comunidad resolvió las transformaciones en su entorno al instaurar una frontera simbólica entre quienes estuvieron previo al cambio de administración y quienes llegaron a raíz de este. Trazar una línea de separación que reflejara un distanciamiento, en términos intelectuales y morales, ha sido la condición de posibilidad para que puedan permanecer y compartir varios miembros el mismo lugar.

De ahí que, para la comunidad, la pornografía resida "abajo" y que, para el concurso "Miss y Mr. Foro", ubicado en la parte superior de la página haya una relativización o una ambigüedad. Poder precisarla implica conocer aquello que es o podría ser pornografía y aquello que no. En caso de existir una conformidad sobre la publicación de pornografía en el "Miss y Mr. Foro", se estaría indicando que no hay una distinción entre "arriba" y "abajo". Dicho de otro modo: los procesos constitutivos de la comunidad son los que marcan la comprensión y vivencia de la pornografía. 
La conjunción comunidad y pornografía, desde diversas ópticas, se entendería casi como un oxímoron. Por un lado, la comunidad ha sido constantemente pensada y definida bajo nociones asociadas a la armonía, la homogeneidad y el trabajo sobre el bienestar común. En algunos autores clásicos como Émile Dukheim (2001a, 2001b), Max Weber (2002), Enrique Dussel (1986) y en otros autores contemporáneos como Howard Rheingold (1996), Nicolas Negroponte (1999), Pierre Lévy (1999), Roman Gubern (2007), se pueden ubicar nociones sobre comunidad ancladas a las pertenencias, atributos y propiedades que los sujetos tengan en común.

Por otro, la pornografía se concibe bajo una lógica individual, anclada a los objetos (imágenes) y como riesgo o amenaza. Es inusual que estos dos conceptos teóricos se piensen de manera distinta, por ejemplo, que comunidad signifique conflicto, heterogeneidad, negación, malestar. En este sentido, el texto de Roberto Esposito, Communitas: origen y destino de la comunidad (2003) es útil para entender esta idea. El autor considera la comunidad como una constante exposición y enfrentamiento que la hace posible. Lejos de entenderse la comunidad como un hecho a partir de "lo común", se piensa como proceso a partir de la negación de lo "común". Es decir, a partir de la necesidad constante de interacción, sin llegar a un estado acabado y certero de comunidad porque siempre está haciéndose.

Tampoco es frecuente que en la pornografía prime la colectividad, los procesos y el mutuo apoyo o complicidad, como he tratado de reseñar en los apartados anteriores. La trampa sería creer que existe en este nexo algo novedoso, llamativo, exótico o particular. Muy por el contrario, dadas las condiciones de posibilidad en términos intelectuales o académicos, se vuelve un sobreesfuerzo pensar la comunidad y la pornografía desde otro lugar.

\section{Comprensión como proceso o cosa}

Los abordajes de la pornografía como esencia y como construcción dejan como saldo la reproducción de dicotomías con las que, en apariencia, se ha deseado distanciarse analíticamente. Sin embargo, como he intentado argumentar, se trata de una misma línea que ve en la pornografía un objeto, un hecho. A partir de la ecología de los materiales, Tim Ingold sostiene que, en lugar de hablar de objetos, podemos hablar de cosas, para fijar la atención en el potencial y movimiento de los materiales -fabricación, crecimiento, transformación- ${ }^{4}$. En palabras del autor "nada nunca está terminado: todo puede ser algo, pero siendo algo se está siempre en el camino de convertirse en otra cosa. ... Prosiguen, superando a los destinos formales que, en un momento u otro, se les ha asignado" (Ingold, 2014, p. 9). Este

4 Cabe destacar que Tim Ingold hace este planteamiento inspirado en el ensayo "La cosa" de Martin Heidegger (1994), incluido en su libro Conferencias y artículos.

ESCENA. Revista de las artes, 2020, Vol. 80, Núm. 1 (julio-diciembre), pp.262-282 
cambio analítico implicaría, entonces, para efectos de esta argumentación, reconocer que la pornografía no es una imagen creada para que sea consumida, usada o reciclada. Más bien, es la reunión de materiales en formación permanente (sin estatus culmen), en donde, por supuesto, nos encontramos como organismos en estrecha correspondencia.

En una misma línea de pensamiento, Anne Fausto-Sterling (2006), desde las teorías de sistemas ontogénicos, niega la existencia de dos únicos tipos de desarrollo de la sexualidad humana: uno, el guiado por los genes, hormonas y cédulas (naturaleza); el otro, orientado por el medio ambiente, la experiencia, aprendizaje o fuerzas sociales (crianza). En su defecto, a partir de los sistemas ontogénicos se establece una indivisibilidad o continuum entre lo biológico y lo social, así como el reconocimiento de los organismos (humanos o no) como procesos activos (Fausto-Sterling, 2006).

Este último punto es de especial relevancia, debido a que la crítica desarrollada por diversos autores se concentra en la separación de antaño entre el mundo humano y el mundo no-humano, entre forma y materia. En muchos ámbitos disciplinares, estas dualidades se siguen reproduciendo: cuando se analizan los materiales, los organismos vivos quedan por fuera y viceversa. En gran medida, esta disyuntiva es la que se puede encontrar en las investigaciones sobre pornografía citadas anteriormente, en las cuales no se toma en cuenta a poblaciones o grupalidades específicas (organismos) y sus entornos, sino que se da prioridad al contenido de las imágenes para así inferir algo acerca de las personas y su comportamiento. Es decir, no hay una preocupación por tomar en cuenta la correspondencia que, como organismos vivos, tenemos dentro de lo que alcancemos a comprender y estudiar como pornografía.

Ingold (2013) se pregunta "¿no podría ese involucramiento [correspondencia], o sea el trabajar directamente con los materiales, ofrecer un procedimiento de descubrimiento más potente que un enfoque inclinado hacia el análisis abstracto de las cosas ya hechas?" (p. 21). En efecto, resulta interesante revisar trabajos etnográficos desde los cuales hay un profundo involucramiento por parte de quien investiga, aunque el punto de partida para entender la pornografía continúa dándose en términos objetuales. Las tesis de María Elvira Díaz-Benítez (2009) y de Héctor Guillén Rauda (2013) son muy significativas en este sentido. Díaz-Benítez (2009) explora, en la ciudad de Sao Paulo, las redes del sexo que se establecen en cinco productoras de material porno, desde el reclutamiento de personas y la producción filmica, hasta la posproducción y distribución. A lo largo de su texto, es posible entrever la multiplicidad de interacciones, de personas, de prácticas. Pero, la pornografía es pensada como objeto, en tanto su entendimiento pasa por la creación de una imagen (en este caso, de los filmes), que tiene un inicio y un final. La autora, incluso, establece diferencias entre la fase previa, la de producción y la de consumo. La idea de proceso está anclada a una secuencia hecha, no a un proceso de materiales en desarrollo. 
En la etnografía de Guillén Rauda (2013), el autor centra su trabajo en la ciudad de México y la producción de pornografía amateur en dicha ciudad a través de una editorial llamada Editorial Matlarock. El autor toma como punto de partida la teoría del actor-red (TAR) de Bruno Latour (2008)5. La distinción desde la cual parte la TAR es entre lo humano y lo no-humano, entendidas ambas categorías como actantes, con agencia, no como entes pasivos. Según Latour (2008), que un actante no-humano tenga agencia significa:

Además de "determinar" y servir como "telón de fondo de la acción humana", las cosas podrían autorizar, permitir, dar los recursos, alentar, sugerir, influir, bloquear, hacer posible, prohibir, entre otros. La TAR no es la afirmación vacía de que son los objetos los que hacen las cosas "en lugar de" los actores humanos: dice simplemente que ninguna ciencia de lo social puede iniciarse siquiera si no se explora primero la cuestión de quién y qué participa en la acción, aunque signifique permitir que se incorporen elementos que, a falta de un mejor término, podríamos llamar no-humanos. (p. 107)

De manera que, a la luz del planteamiento de Latour, para Guillén Rauda (2013) la pornografía está asociada a lo no-humano. En consonancia con Díaz-Benítez (2009), este autor estudia un proceso de producción y comercialización del sexo, de la pornografía como objeto, pero, en este caso, se le reconoce una "agencia". Cabe observar que en el trabajo de Guillén Rauda nunca quedan claros los límites o bordes de la agencia como tal, no se logra saber con certeza cuándo la pornografía posee agencia o si siempre la posee.

Tim Ingold, por cierto, critica tales planteamientos, ya que existe una lógica animista en tanto existe algo ajeno o algo en su interior que las anima ("un espíritu"). A fin de cuentas, simplemente al objeto solo se le está otorgando cierta capacidad o rango de acción; traer las cosas a la vida. Dice Ingold (2013)

No consiste en espolvorearlas con agencia, sino devolverlas a los flujos generativos del mundo de materiales en el que se originaron y en donde continúan subsistiendo. Este punto de vista, en el que las cosas están en la vida y no la vida en las cosas, se opone a la comprensión antropológica del animismo. (p. 33)

Ambas etnografías, aunque no se desmerita ni se pone en duda su valioso aporte a la antropología, permanecen inscritas en aquellas nociones constructivistas sobre la pornografía que la comprenden como objeto. Esta posición teórica, como he destacado, apela a la dimensión subjetiva, experiencial e interpretativa de las personas, que gira en torno a las imágenes. En el apartado anterior, expliqué la necesidad de dar cuenta de una para comprender la otra. Sin embargo, acá quisiera conectarlo de manera más directa con el planteamiento de Ingold sobre las cosas.

${ }^{5}$ En inglés, "ANT" que significa "Actor-Network Theory".

ESCENA. Revista de las artes, 2020, Vol. 80, Núm. 1 (julio-diciembre), pp.262-282 
En la descripción etnográfica sostuve que, en términos teóricos, enlazar comunidad y pornografía es una tarea complicada. Ambas se han definido de forma incompatible. Pero, podríamos ver más categorías de la misma naturaleza en el Foro de Costa Rica y las denominaciones académicas a la hora de pensar la pornografía, las cuales e comparo en la Tabla 2.

Tabla 2. Comparación de las categorías del Foro de Costa Rica y las categorías académicas

\begin{tabular}{|c|c|c|}
\hline Procedencia & Foro de Costa Rica & Académicas \\
\hline \multirow{8}{*}{ Categorías } & \multirow{4}{*}{$\begin{array}{l}\text { Arriba/abajo. } \\
\text { Nick masculinizado/ }\end{array}$} & Humano/No humano \\
\hline & & Esencialistas/Construccionistas \\
\hline & & Discusiones objetivas/discusiones subjetivas \\
\hline & & Definición/adjetivación \\
\hline & \multirow{4}{*}{ Miss/Mr. } & Softcore/hardcore \\
\hline & & Efecto positivo/efecto negativo \\
\hline & & Porno para hombres/porno para mujeres \\
\hline & & Pornografía/Pospornografía \\
\hline
\end{tabular}

Fuente: Elaboración propia.

Las visiones dualistas son insuficientes en términos analíticos para discutir sobre comunidad y pornografía en un mismo plano. La comprensión de un continuum entre los procesos constitutivos de la comunidad y de la pornografía implica situar a ambas como cosa. Con esto, hay un distanciamiento de las posiciones dicotómicas y se les reconoce en constante tomar-forma, por lo que es necesario

Ser capaz de contar sus historias - de lo que hacen y lo que les sucede cuando son tratados en formas particulares- en la práctica misma de trabajar con ellos ... Los materiales, por lo tanto, continúan, sufriendo modulación continua a medida que lo hacen. En el mundo fenoménico, todo material es un devenir. (Ingold, 2014, p. 8)

En el ejercicio de "contar la historia", se puede decir que la escisión del foro entre "arriba" y "abajo" indica la diferencia entre el concurso "Miss y Mr. Foro" y la pornografía, y las razones por las cuales tuvo cabida. Se observa, entonces, que la definición y marco de referencia de la pornografía se encuentra anclada a relaciones, en entornos en constante desarrollo y no precisamente en imágenes. 


\section{Conclusiones}

Aquella clase del 11 de junio, en la UNAM, resultó enriquecedora porque hubo un intento de trascender la imagen. Hubo un proceso de negociación en el cual no siempre coincidimos en los propósitos y sentidos de la pornografía. Pasamos por temas relacionados al deseo, la moral, el trabajo, la institucionalidad, los modos de producción, la materialidad y los materiales; discutimos sobre pornografía a partir de imágenes que en un principio las personas no categorizaron como tal.

Si la pornografía fuese esencia o construcción, con seguridad el grupo de la clase y la comunidad del foro no hubiese tenido complicación en manifestar, de inmediato, "veo pornografía", "esto es pornografía". Sin embargo, en el ensayo he intentado retomar críticamente ese tipo de tradición reflexiva e investigativa que define y adjetiva y, con ello, legitima una y otra vez su determinación como objeto, con resultados no del todo satisfactorio en términos comprensivos.

Pese a que buena parte del texto aborda las imágenes, el afán fue siempre posicionarse en contra de estas. De fondo, este es un argumento contra los objetos. La argumentación planteada es a favor de procesos, a favor de las cosas, de los materiales en ese constante estar siendo. La comprensión de la pornografía entendida como cosa lleva a pensarla como algo inacabado, siempre en potencia, en un devenir. ¿Por qué sería importante comprender la pornografía como cosa o proceso? Siguiendo a Fausto-Sterling (2006), cuando se pregunta "¿qué es lo que ganamos al escoger esta teoría [de sistemas ontogénicos] como marco analítico?" (p. 42), la autora refiere a que, si bien este posicionamiento no es un filtro mágico, brinda más claridad, coherencia y consistencia para interpretar los datos. No funciona para dar cuenta de una verdad fundamental, pero si funciona para entender el mundo más allá de dicotomías que pueden resultar peligrosas.

Las definiciones y las adjetivaciones de la pornografía anuncian una predisposición hacia la creación límites y distinciones. Es válido reconocer que, en algunos casos, tales ejercicios están animados por defender una democratización de cuerpos y placeres, por cuestionar un orden patriarcal y violento que halla su nicho en sectores más industriales y comerciales. Pero, no deja de ser inquietante que, cuando se cuestiona si las imágenes de desnudo genital son o no pornografía, cuando se describe el porno para hombres y el porno para mujeres, cuando se contrapone la pornografía y la pospornografía, se apunta a rupturas que siguen basándose en imágenes y en dicotomías, no en un continuum basado en procesos emergentes. Podríamos dedicarnos a elaborar más etiquetas o categorías pensado que así tendremos un mundo más equitativo, plural e inclusivo, pero "no son válidas en absoluto y solo se comprenden bien en términos de acontecimientos ontogénicos únicos que afectan a individuos particulares" (Fausto-Sterling, 2006, p. 44).

ESCENA. Revista de las artes, 2020, Vol. 80, Núm. 1 (julio-diciembre), pp.262-282 
Con esto en mente, quisiera cerrar este ensayo con un caso que recientemente se presentó en el ámbito judicial costarricense. En mayo del 2019, a raíz de una alerta por parte del gobierno canadiense, se abrió un proceso penal en contra de una persona de 17 años por la fabricación de "pornografía virtual" o "pseudo pornografía" y su publicación en una página web6. La pornografía virtual o pseudopornografía es tipificada como delito en Costa Rica desde el año 2013. De acuerdo al Código Penal (2018) se establece en el artículo 174bis:

Se impondrá pena de prisión de seis meses a dos años al que posea, produzca, venda, distribuya, exhiba o facilite, por cualquier medio, material pornográfico en el que no habiendo utilizado personas menores de edad:

a) Emplee a una persona adulta que simule ser una persona menor de edad realizando actividades sexuales.

b) Emplee imagen, caricatura, dibujo o representación, de cualquier clase, que aparente o simule a una persona menor de edad realizando actividades sexuales. (p. 117)

Al parecer la persona de 17 años ha difundido dibujos y videos de tipo manga-animé. Por ahora, no se ha encontrado una conexión con redes de explotación de menores de edad ni daños o perjuicios a terceras personas. Todavía el caso sigue en investigación por parte del Organismo de Investigación Judicial (OIJ).

Los elementos de distinción y análisis dentro del ámbito judicial parten de una visión a priori de la pornografía. No solo estamos ante una mirada asexualizada de la infancia o niñez. También, en este caso particular, no hay personas adultas de por medio como productores; más bien se trata de una persona menor de edad, quien no se encuentra tampoco vinculada con redes delictivas. Aquí, se ponen en tensión diversas consideraciones: entre lo que, en un momento, fue creado como manga-animé, en otro se transformó en pornografía virtual o pseudopornografía. Así, aún siguen desplegándose procesos de negociación en medio de indagaciones y elaboración de evidencias.

En los sistemas judiciales la pornografía virtual, la pseudopornografía o la pornografía virtual infantil ha sido tema de preocupación en otras latitudes, tales como Gran Bretaña (Nair, 2010), Estados Unidos (Oxman, 2011), España (Agustina, 2010; Valencia Rodríguez, 2014) y Colombia (Romero Hernández, 2017). Justamente, es en estas situaciones donde

6 Para más detalles sobre esta noticia, se pueden consultar las notas de prensa "Investigan a menor sospechosa de difundir pornografía tipo caricaturas" del periódico digital CRHoy (2019, 16 de mayo) y "Menor de 17 años difundió en blog 146 imágenes pornográficas en maga y animé" del periódico La Nación (2019, 17 de mayo).

ESCENA. Revista de las artes, 2020, Vol. 80, Núm. 1 (julio-diciembre), pp. 262-282 
no alcanzan las nociones esencialistas y constructivistas, las objetivas y las subjetivas, debido a que la tipificación como delito se basa en imágenes y sujetos específicos. De nuevo, el centro está en objetos: contenido de las representaciones, persona adulta (con capacidad de sexualización), persona menor de edad (sin capacidad de sexualización). Comprender la pornografía como cosa es otra forma de preguntarnos por el proceso, lo que está siendo y no por lo que ya es o está.

\section{Referencias}

Agustina, J. R. (2010). ¿Menores infractores o víctimas de pornografía infantil? Respuestas legales e hipótesis criminológicas ante el Sexting. Revista Electrónica de Ciencia Penal y Criminología, (12-11), 1-44.

Arcand, B. (1993). El jaguar y el oso hormiguero. Antropología de la pornografía. Buenos Aires: Ediciones Nueva Visión.

Ares, L., \& Pedraz Poza, S. A. (2011). Sexo, poder y cine: relaciones de poder y representaciones sexuales en los nuevos relatos pornográficos. Icono14, 9(3), 98-119. Recuperado de http://dialnet.unirioja.es/servlet/articulo?codigo=3963231\&info=resumen\&idioma $=\mathrm{ENG}$

Azar, M. (2014). La industria del porno. Cine, tecnología y sexualidad. Apuntes de investigación del CECYP, 23(24), 123-139. Recuperado de http://www.scielo.org.ar/ pdf/aicecyp/v23n2/v23n2a01.pdf

Baudrillard, J. (1981). De la seducción. Madrid: Ediciones Cátedra.

Baudrillard, J. (1994). La simulación en el arte. En La ilusión y la desilusión estéticas (pp. 18-39). Caracas: Monte Avila Editores. https://doi.org/10.1093/fs/knl157

Código Penal. (2018). San José: Investigaciones Jurídicas S.A.

del Barrio-Álvarez, E., \& Garrosa, E. (2015). ¿Educando en igualdad? Análisis de la triada pornografía- discriminación-violencia. Feminidad y masculinidad en la pornografía convencional. Journal of Feminist, Gender and Women Studies, (1), 29-39.

Díaz-Benítez, M. E. (2009). Nas redes do sexo: Bastidores e cenários do pornô brasileiro. Universidade Federal do Rio de Janeiro, Museu Nacional, PPGAS. Universidade Federal do Rio de Janeiro. Recuperado de http://teses2.ufrj.br/Teses/PPGAS_D/ MariaElviraDiazBenitez.pdf

Díaz-Benítez, M. E. (2013). El quehacer porno en la construcción de imágenes de espectacularidad. Memoria y Sociedad, 17(34), 92-109.

Dukheim, É. (2001a). La división del trabajo social. Madrid: Akal. 
De objeto a cosa. Una reflexión para comprender

Artículo

la pornografía

Dukheim, É. (2001b). Las reglas del método sociológico. México, D.F: Fondo de Cultura Económica.

Dussel, E. (1986). Ética comunitaria. Madrid: Paulinas.

Echavarren, R. (2014). Las fronteras del porno. Ensayo sobre la invención literaria de la pornografía y sus avatares tecnológicos. Lexington, KY: La Flauta Mágica.

Erchull, M. J., \& Liss, M. (2014). The object of one's desire: How perceived sexual empowerment through objectification is related to sexual outcomes. Sexuality and Culture, 18(4), 773-788. https://doi.org/10.1007/s12119-013-9216-z

Esposito, R. (2003). Communitas. Origen y destino de la comunidad. (C. R. Molinari Marotto, Trad.) Buenos Aires, Argentina: Amorrortu.

Fausto-Sterling, A. (2006). Cuerpos sexuados. La política de género y la construcción de la sexualidad. Barcelona: Melusina.

García del Castillo, A. (2011). Asalto al poder en el porno: apropiación y empoderamiento en las narraciones postpornográficas. Icono14, 9(3), 361-377. Recuperado de http://dialnet.unirioja.es/servlet/articulo?codigo=3963285\&info=resumen\&idio$\mathrm{ma}=\mathrm{SPA}$

Giménez Gatto, F. (2015). Pospornografías. México, D.F: La Cifra Editorial.

González Ramírez, R. M. (2011). Mar de indicios. Imágenes de la violencia feminicida y la pornografía sádica en Ciudad Juárez. Estudios de Antropología Sexual, 1(3), 135-154.

Griffith, J. D., Adams, L. T., Hart, C. L., \& Mitchell, S. (2012). Why become a pornography actress? International Journal of Sexual Health, 24(3), 165-180. https://doi.org $/ 10.1080 / 19317611.2012 .666514$

Gubern, R. (2005). La imagen pornográfica y otras perversiones ópticas. Barcelona, España: Anagrama.

Guillén Rauda, H. D. (2013). Desnudando al porno. Controversias en torno a la comercialización del sexo a través del proceso de producción de pornografía amateur: la Editorial Matlarock en México. Universidad Autónoma Metropolitana Unidad Iztapalapa.

Guillén Rauda, H. D. (2014). La performance como herramienta analítica del proceso de producción de pornografía amateur en México. México, D.F: UNAM.

Heidegger, M. (1994). Conferencias y artículos. (E. Barjau, Trad.). Barcelona: Serbal. Recuperado de http://medicinayarte.com/img/heidegger_conferencias_articulos.pdf

ESCENA. Revista de las artes, 2020, Vol. 80, Núm. 1 (julio-diciembre), pp. 262-282 
Ingold, T. (2013). Los Materiales contra la materialidad. Papeles de Trabajo, 7(11), 19-39.

Ingold, T. (2014). Hacia una ecología de los materiales. Annual Review of Anthropology, 41, 427-442.

Kendrick, W. (1995). El museo secreto. La pornografía en la cultura moderna. (J. E. Jaramillo-Zuluaga, Trad.). Colombia: Cultura Libre.

Latour, B. (2008). Reensamblar lo social: una introducción a la teoría del actor-red. (G. Zadunaisky, Trad.). Buenos Aires: Manantial.

Lawrence, D. H. (2013). Pornografía y obscenidad. (M. Sanders, Trad.). San José, Costa Rica: Uruk Editores.

Leal Guerrero, S. (2013). Cuerpos deseados / machos representados. Aphrodisia, fórmulas representacionales y fotografía en la interacción homoerótica mediada por Internet. Sexualidad, Salud y Sociedad, (13), 113-143.

Lévy, P. (1999). ¿Qué es lo virtual? Barcelona: Paidós.

Llorente, M. E. (2017). Erotismo y pornografía: revisión de enfoques y aproximaciones al concepto de erotismo y de literatura erótica. Anuario de Letras. Lingüística y Filología, 5(1), 359-375.

Lust, E. (2008). Porno para mujeres. Barcelona, España: Editorial Melusina, S.L.

Monge-Nájera, J., \& Vega Corrales, K. V. (2013). Sexual videos in Internet: a test of 11 hypotheses about intimate practices and gender interactions in Latin America. Cuadernos de Investigación UNED, 5(2), 333-338.

Nair, A. (2010). Real porn and pseudo porn: The regulatory road. International. Review of Law, Computers and Technology, 24(3), 223-232.

Negroponte, N. (1999). El mundo digital. Barcelona: Ediciones B.

Ogien, R. (2005). Pensar la pornografía. Barcelona: Paidós.

Osborne, R. (2002). La construcción sexual de la realidad. Un debate en la sociología contemporánea de la mujer. Madrid: Ediciones Cátedra.

Oxman, N. (2011). Aspectos político-criminales y criminológicos de la criminalización de la posesión de pornografía infantil en Estados Unidos de Norteamérica. Política Criminal, 6(12), 252-294.

Parreiras, C. (2010a). Internet e mercado erótico: notas etnográficas sobre x-sites.

Parreiras, C. (2010b). Just click here: Notas sobre genero e sexualidade em práticas e 
corpos ciber-pornos. En Fazendo Gênero 9. Diásporas, Diversidades, Deslocamentos (pp. 1-9). Florianópolis, Brasil.

Parreiras, C. (2016). Pornografias.com: As convencoes do altporn, espaco urbano e redes. En IX Simpósio Nacioanal ABCiber -PUC Sao Paulo. Recuperado de: abciber.org.br/anaiseletronicos/wp-content/uploads/2016/trabalhos/pornografias_ com_as_convencoes_do_altporn_espaco_urbano_e_redes_carolina_parreiras.pdf

Retana, C. (2008). Pornografía: la tiranía de la mirada. San José, Costa Rica: Arlekín.

Rheingold, H. (1996). La comunidad virtual. Una sociedad sin fronteras. Barcelona: Gedisa.

Romero Hernández, M. (2017). Tecnología y pornografía infantil en Colombia, 20132015: interpretación desde un enfoque victimológico. Revista Criminalidad, 59(1), $27-47$.

Salinas Hernández, H. M. (2011). El porno gay hecho en México. Cuicuilco, 18(52), 225-249.

Tena Aguiar, Y. (2015). La Post-pornografía: una respuesta crítica a la Pornografía Castrante. Universidad de la Laguna

Sontag, S. (2014). Estilos radicales. Barcelona: Debolsillo.

Tenorio Pangui, L. F. (2015). Pornografía, pedagogía y pospornografía en Internet: teoría de género de dos videos. Estudios de Antropología Sexual, 1(6), 102-115.

Valencia Rodríguez, N. (2014). Pornografía virtual infantil. Universitat Autònoma de Barcelona.

van Doorn, N. (2010). Keeping it Real. User-Generated Pornography, Gender Reification, and Visual Pleasure. Convergence: The International Journal of Research into New Media Technologies, 16(4), 411-430. DOI: 10.1177/1354856510375144

Weber, M. (2002). Economía y sociedad. Esbozo de sociología comprensiva. Madrid: Fondo de Cultura Económica.

Yehya, N. (2012). Pornografía. Obsesión sexual y tecnológica. México, D.F: Tusquets Editores.

Zhou, Y., \& Paul, B. (2016). Lotus Blossom or Dragon Lady: A content analysis of "Asian Women" online pornography. Sexuality and Culture, 20(4), 1083-1100. https://doi. org/10.1007/s12119-016-9375-9 